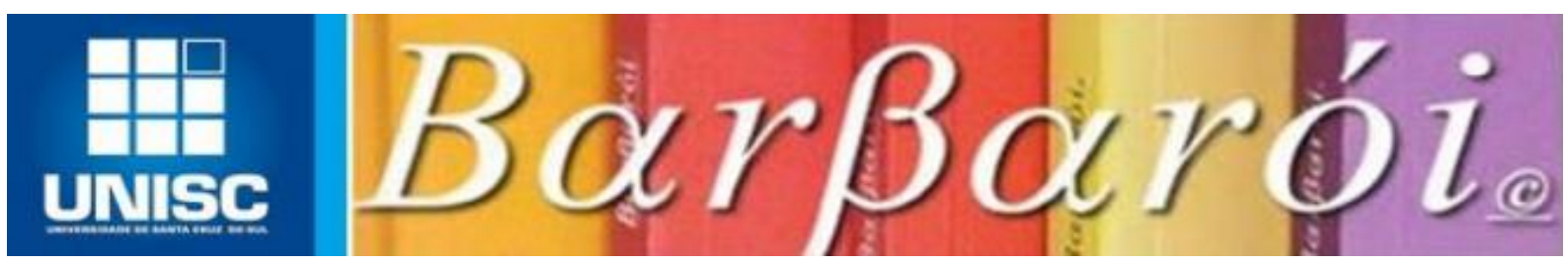

\title{
AS FRONTEIRAS (IN)VISÍVEIS ENTRE AS JUVENTUDES QUILOMBOLA E URBANA
}

\section{DOI: http://dx.doi.org/10.17058/barbaroi.v2i52.13025}

\author{
Roseane Amorim da Silva \\ Universidade Federal de Pernambuco - UFPE - Brasil \\ Jaileila de Araújo Menezes \\ Universidade Federal de Pernambuco - UFPE - Brasil
}

\section{RESUMO}

No presente estudo podem ser observados alguns aspectos que emergem dos encontros entre os/as jovens rurais quilombolas e jovens urbanos/as. Através dos/as quilombolas buscou-se conhecer como acontecem esses encontros. Os/as quilombolas fazem parte de uma pesquisa realizada em duas comunidades, localizadas na área rural do município de Garanhuns/PE, cujos nomes são Castainho e Estivas. A pesquisa foi realizada em dois momentos: no primeiro aconteceu a observação participante nas comunidades, em seguida 20 entrevistas semiestruturadas com os/as jovens. Os dados construídos foram analisados a partir da interseccionalidade de gênero, raça e classe social. Foi visto que os/as jovens da cidade frequentam as comunidades quilombolas, principalmente nos finais de semana, onde têm práticas de lazer. Os/as jovens quilombolas frequentam a área urbana com finalidades diversas: estudos, trabalho, festas. Percebe-se que esse encontro entre as juventudes no contexto quilombola, muitas vezes, é atravessado por situações de opressão e desigualdades. Os/as jovens urbanos fazem uso do território quilombola sem restrições, ligam som em alto volume, bebem, escolhem o lugar do bar onde querem ficar, o mesmo não acontece quando os/as quilombolas rurais estão na cidade. As relações desiguais de classe, raça e gênero são marcadas no próprio território quilombola, a exemplo dos/as jovens urbanos que frequentam as comunidades, mas não se "misturam" com as pessoas de lá. Considera-se importante observar essa realidade, uma vez que buscou-se compreender as vivências dos/as jovens no intuito de visibilizar limites e possibilidades que circunscrevem a vida das juventudes.

Palavras-chave: jovens quilombolas; jovens urbanos; interseccionalidade

\section{Introdução}

A literatura sobre juventude rural revela que os contextos rurais e urbanos estão em comunicação permanente. Realidade que tem sido ampliada, nos últimos anos, através da intensa mobilidade dos atores e atrizes sociais entre os diversos espaços (PEREIRA, 2004; CARNEIRO, 1998). Estudar a juventude rural implica a compreensão de uma dupla dinâmica social, "por um lado uma dinâmica espacial que relaciona a casa (a família), à vizinhança (a comunidade local) e por outro, à cidade (o mundo urbano-industrial)" (WANDERLEY, 2007, 
p.23). São nesses espaços e a partir dessas relações que os/as jovens vão experienciando e constituindo-se enquanto sujeitos sociais. No entanto, como observado no presente estudo, o encontro entre as juventudes quilombolas/rurais e os/as jovens da cidade, muitas vezes, é atravessado por situações de opressão e desigualdades sociais.

O presente estudo foi realizado nas comunidades quilombolas, e fez parte da pesquisa para construção da dissertação de mestrado no programa de Pós-graduação em Psicologia da Universidade Federal de Pernambuco - UFPE. A dissertação tem como título: Os significados do uso de álcool entre os/as jovens: uma perspectiva interseccional. A pesquisa foi realizada em duas comunidades, localizadas na área rural do município de Garanhuns/PE, cujos nomes são: Castainho e Estivas. Foi visto que os/as jovens quilombolas frequentam a área urbana do município com diversas finalidades: estudo, trabalho, lazer, busca por atendimento médico, entre outras. E observou-se também, que os/as jovens urbanos/as costumam frequentar as comunidades, principalmente nos finais de semana. Esse encontro entre as juventudes no contexto quilombola chamou atenção e através dos/as jovens das comunidades buscou-se conhecer como acontecem esses encontros, e as relações estabelecidas entre os/as jovens de ambos os territórios.

Na luta das populações tradicionais existe um campo de preocupações no sentido de garantia de direitos à população quilombola, no que se refere à educação, saúde, lazer, oportunidades de trabalho e a posse das terras. Há muitos anos existe uma grande luta das comunidades pelo reconhecimento enquanto quilombolas, a titulação e a posse das terras. Para essas comunidades a posse da terra é fundamental para que lutem por outros direitos. ${ }^{1}$

Importante abordar aqui, o que são comunidades quilombolas. Os quilombos surgiram no país como um modo de organização social e coletiva dos/as negros/as em resistência. O que aconteceu por meio de fugas, reorganização comunitária e outras formas para não se submeterem à escravidão. Anos mais tarde, os quilombolas ganharam visibilidade com a Constituição de 1988, como reparação pela violação dos direitos e compensação de uma injustiça histórica. Embora o que esteja na constituição, na prática ainda está longe de ser alcançado. A identidade quilombola está associada à ideia de pertencimento a um território,

\footnotetext{
${ }^{1}$ Diferente da região onde fizemos a pesquisa, uma área rural, existem também em outras localidades os quilombos urbanos, unidades móveis que se formaram no Brasil imperial, principalmente nas grandes cidades escravistas, como Rio de Janeiro, Salvador e Recife. Eram espaços de proteção e/ou esconderijo para os milhares de fugitivos noticiados na imprensa diariamente. Os quilombos suburbanos de Salvador foram os que ficaram mais conhecidos desde o século XVIII, com destaque para os mocambos do Urubu e outros estabelecidos próximo a Itapuã. Nos subúrbios do Recife, essa movimentação teve nome e líder: o Quilombo do Catucá era comandado por um chefe temido chamado Maluguinho (GOMES, 2018).
} 
aos laços de parentesco, aos valores, e costumes (SANTANA; TELES; OLIVEIRA, 2017). Existe uma predominância de negros nessas comunidades, mas não são todos/as os/as quilombolas que têm o fenótipo negro.

Cruz (2007, p.94) ressalta que "as populações tradicionais têm se organizado, ganhando visibilidade e protagonismo, se constituindo e afirmando como sujeitos políticos na luta pelo exercício ou mesmo pela invenção de direitos a partir de suas territorialidades e identidades territoriais". Todavia, ainda é presente no imaginário popular o quilombo como algo pertencente ao passado, e quando ficam sabendo da existência de comunidades quilombolas, algumas pessoas têm uma imagem estereotipada sobre os/as moradores/as dessas comunidades, por desconhecerem o modo de vida e as pessoas que fazem parte desse contexto.

No território nacional, há mais de 1.500 comunidades quilombolas que foram certificadas pela Fundação Cultural Palmares.Em Pernambuco existem comunidades quilombolas em vários municípios. Dados da Fundação Cultural Palmares revela que até agosto de 2013, 108 comunidades foram reconhecidas no estado como remanescentes de quilombos.Em Garanhuns, onde se localizam as comunidades estudadas, existem 6 comunidades: Castainho, Estivas, Timbó, Estrela, Tigre e Caluete. Castainho e Estivas são reconhecidas pela Fundação Cultural Palmares, mas a luta pela posse do território também é uma realidade dessas comunidades.

Observou-se na literatura sobre juventude que algumas pesquisas têm se debruçado para compreender algumas questões voltadas para as vivências dos/as jovens quilombolas. Em uma pesquisa realizada em um quilombo localizado no interior de São Paulo, comunidade Ivanporunduva, foi visto que ocorreram mudanças culturais decorrentes da influência do meio urbano, a exemplo da inserção da televisão. A chegada da televisão fez com que mudasse o horário das festas para que não fosse preciso perder as novelas, os jargões foram introduzidos no vocabulário da comunidade, e os/as moradores/as mais velhos/as passaram a perceber a televisão como instrumento que estaria contribuindo para a mudança de comportamento dos/as jovens (ALMEIDA, 2005). Não só a televisão que há muito tempo já faz parte das diversas culturas, mas também a circulação dos/as jovens no meio urbano têm contribuído para uma mudança no modo de se vestir, de se comportar e na aspiração por projetos de vida diferenciados das gerações passadas, conforme foi possível observar na pesquisa realizada. 
Em outro estudo com as jovens do quilombo São José, localizado no Rio de Janeiro, pôde ser visto que elas saem de sua comunidade para trabalhar, principalmente como domésticas nos centros urbanos mais próximos. Contudo, esse deslocamento não significa necessariamente ruptura com a comunidade de origem, assim como em outros contextos rurais (BASTOS, 2009). O que corrobora com um estudo realizado por Carneiro (1998), em que foi visto que a mobilidade dos jovens rurais supõe uma negociação entre, de um lado, a identidade relacionada à cultura da comunidade rural e às relações afetivas com a família e, de outro, um projeto individualizado, que supõe uma autonomia diante das redes familiares.

Sobre as relações tecidas no espaço rural-urbano, em pesquisa sobre jovens nas áreas rurais do município de Friburgo, localizado no Estado do Rio de Janeiro e de Nova Pádua, no Rio Grande do Sul, Carneiro (1998) chamou atenção para a proximidade existente entre núcleos urbanos representativos, bem como a facilidade de acesso à cidade pelos habitantes do meio rural. A integração rural-urbana pode abrir algumas possibilidades para os/as jovens rurais, a exemplo da continuidade do processo de escolarização e das escolhas profissionais. Como afirma Castro (2006, p. 266) "a vivência marcada pela circulação e socialização em espaços considerados urbanos e rurais aparecem como o somatório de possibilidades e sonhos no campo do desejo, ainda que a realidade possa construir outros caminhos".

Foi observado por Pereira (2004), em contexto de um assentamento rural no Rio de Janeiro, que a circulação entre as áreas rurais e urbanas, tem início para alguns na época dos estudos, já que as áreas rurais dispõem apenas de escolas que, em geral, oferecem até a $4^{\mathrm{a}}$ série, ou não há escolas, e, em um segundo momento, na busca de trabalho remunerado. $\mathrm{O}$ estudo, trabalho e as festas são os principais fatores que motivam a circulação dos/as jovens rurais no meio urbano. Tais fatores também são motivadores aos jovens das comunidades quilombolas por nós estudadas para que os/as mesmos/as frequentem os espaços urbanos.

Novos desafios são colocados para os/as jovens rurais que estão cada vez mais inseridos no contexto urbano. Suas experiências falam ao mesmo tempo de uma identidade local, mas que recebem influências de lugares diferentes. O campo de possibilidade de realização de suas projeções quanto ao futuro, por exemplo, foi ampliado como resultado da complexificação das relações entre campo e cidade, assim como seus comportamentos passam a se aproximar dos/as jovens que eles/as consideram urbanos/as (PEREIRA, 2004). Os/as jovens rurais estão vivendo experiências que permitem elaborar e reelaborar práticas a partir de valores dos dois universos culturais. 
No presente estudo está sendo relacionada a juventude quilombola também à ruralidade, pois as comunidades quilombolas estudadas são localizadas na área rural e o modo de vida é semelhante a outros contextos rurais, o trabalho na agricultura e no cuidado dos animais, e enfrentam algumas dificuldades, a exemplo da falta de água encanada, saneamento básico, e outras questões vivenciadas por essas áreas. Mas cientes de que a identidade étnica/racial e o processo histórico de constituição dessas comunidades são diferentes, bem como suas lutas.

$\mathrm{Na}$ presente pesquisa foram observados alguns aspectos que emergem dos encontros entre os/as jovens quilombolas e urbanos/as. Considera-se importante observar essa realidade, uma vez que se buscou compreender as vivências dos/as jovens no intuito de visibilizar limites e possibilidades que circunscrevem a juventude. As duas comunidades que fizeram parte desse estudo, Castainho e Estivas, são localizadas uma próxima a outra, a fonte de renda de ambas está relacionada à agricultura e a comercialização dos produtos nas feiras de Garanhuns e nos municípios circunvizinhos. As comunidades possuem alguns equipamentos sociais, a exemplo de um Centro de Referência da Assistência Social - CRAS Quilombo, uma Unidade de Saúde da Família - USF, que são destinados a atender a todas as comunidades da região, mas que devido a grande demanda, a pequena equipe de profissionais, bem como a falta de estrutura desses equipamentos, os cuidados prestados a população ficam comprometidos. Castainho possui uma escola que funciona até o Ensino fundamental II, e Estivas, uma escola que funciona o Ensino Fundamental I. Em ambas as comunidades existem vários bares e campos de futebol, que são referidos pelos/as jovens como os espaços de lazer existentes.

Não há transporte público na comunidade, isto dificulta inclusive a continuidade do processo de escolarização, existe um ônibus para os/as estudantes, mas às vezes esse quebra, não vai buscar os/as quilombolas, e com isso os/as mesmos/as faltam aula, perdem provas e sofrem as consequências disso. Como referido acima não há equipamentos de lazer, só os campos de futebol e os bares, e quem não gosta de frequentar esses espaços, fica sem opção. A falta de atividades de lazer é algo que compromete a saúde mental e a qualidade de vida das pessoas, conforme visto nos estudos realizado por Gomes et al (2009). É nesse contexto onde os/as jovens participantes do presente estudo se constituem. A seguir será abordado como foi realizada a pesquisa.

\section{Método}

Barbarói, Santa Cruz do Sul, n. 52, p.<131-149>, jul/dez, 2018 
Este estudo é de natureza qualitativa, foi desenvolvido em dois momentos. No primeiro foi realizada a observação participante nos diversos espaços existentes nas duas comunidades localizadas na área rural de Garanhuns/PE: Castainho e Estivas, entre eles na Unidade de Saúde, no Centro de Referência da Assistência Social - CRAS Quilombo, na escola, nos bares e no campo de futebol. Foram realizadas conversas com vários moradores/as de diferentes idades. No segundo momento, foram realizadas entrevistas semiestruturadas com os/as jovens quilombolas com idades entre 18 a 24 anos. As entrevistas foram realizadas na casa de alguns e algumas jovens, no campo de futebol e no CRAS Quilombo. A pesquisa foi aprovada pelo Comitê de Ética em pesquisa da Universidade Federal de Pernambuco. Estamos compreendendo no presente estudo as comunidades quilombolas como área rural e a cidade como área urbana. Não participaram da pesquisa jovens da área urbana, as informações sobre os/as jovens da cidade foram construídas a partir do contato com os quilombolas.

Os dados construídos a partir desses dois momentos foram analisados com base na perspectiva da interseccionalidade de gênero, classe social e raça/etnia. A interseccionalidade trata-se de um conceito que foi construído para dar significado à luta e experiência de mulheres negras, cujas especificidades não encontravam espaço de discussão no debate feminista e no debate anti-racista (CRENSHAW, 1989; CRENSHAW,2002 ). Gênero, classe e raça interagem com outras categorias de diferença e, deste modo, produzem as experiências vividas por mulheres e homens.

Adriana Piscitelli (2008, p.269) ressalta que "as interseccionalidades permitem (pensar como construções de diferença e distribuições de poder incidem no posicionamento desigual dos sujeitos no âmbito global)". Essa produtiva valorização das categorias diferença e poder implicaria uma secundarização relativa da categoria gênero, que no pensamento feminista assumiu lugar central nas últimas décadas, obscurecendo ou subordinando outras formas de diferenciação que produzem desigualdades e opressão.

Em relação às categorias de articulação e corroborando com as autoras que consideram a importância de trabalhar com a interação entre as categorias de diferença, Avta Brah (2006, p.351) pontua que "(estruturas de classe, racismo, gênero e sexualidade não podem ser tratadas como variáveis independentes porque a opressão de cada uma está inscrita dentro da outra - é constituída pela outra e é constitutiva dela)". Por isso, tais fatores estão sendo considerados nesse estudo. É importante ressaltar que os/as jovens quilombolas fazem parte de uma parcela da sociedade em que as oportunidades de educação, trabalho e saúde são escassas, as situações de discriminação e estigmas comumente se fazem presentes, formando 
uma série de questões que vem a favorecer a vulnerabilidade dessa população a vários fatores. Abaixo segue alguns dos resultados, foram usados nomes fictícios para representar os/as jovens, no intuito de resguardar a privacidade dos/as mesmos/as.

\section{Resultados e discussão}

Buscou-se conhecer através dos/as jovens quilombolas se eles/as se consideram jovens e o que significa ser jovem para os/as mesmos/as. Foram vistos os diversos significados relacionados à juventude: associada à idade, muitos/as afirmaram ser jovens por terem 19, 20, 22 anos, outros/as atribuem a juventude características como: saber aproveitar a vida, ter coragem, responsabilidade, liberdade, ânimo para viver, força, alegria. Conforme pode ser observado a seguir:

\footnotetext{
Ser jovem é saber viver com limite de responsabilidade, saber viver, eu me considero jovem porque eu tenho 19 anos, sou jovem ainda (Aybu, M, 19 anos).

É muita diferença ser jovem dos pessoal de idade, o pessoal assim da minha idade, a pessoa curte melhor, porque o pessoal de idade meu Deus do céu, chegou assim seus 45 anos, não tem mais força pra nada, fica assim mole, nós novo tem todo ânimo pra fazer o que nós quer, estudar, tudo, acho que é muito melhor (Chinaka, F, 22 anos).
}

Percebe-se o quanto é atribuído um valor positivo a juventude, e ainda chama atenção como à velhice é percebida pelos/as jovens, um período da vida de inutilidade. Já no discurso de outro jovem é possível ver uma ideia de juventude que faz alusão a não responsabilidade com a família e com o trabalho, sendo esta destinada a vida adulta:

P: Você se considera jovem?

Eu me considero jovem, porque eu acho que a pessoa pra ser assim adulto, adulto a pessoa sente quando tá uma pessoa de responsabilidade, pai de família, trabalho, filho, mulher, mas no momento assim, eu me considero jovem ainda, e porque é recentemente que eu completei os 18, aí eu não posso dizer que sou adulto, tenho que ser real, não posso dizer uma coisa que sou, se eu não sou (Rashid, M, 18 anos).

Este discurso não é algo recorrente na vida dos/as jovens quilombolas, pois alguns desde criança trabalham com os pais na agricultura, e quando crescem, continuam trabalhando na agricultura com mais afinco ou saem em busca de outro trabalho para arrumar o próprio sustento e ajudar a sobrevivência da família, abandonando algumas vezes os estudos e trabalhando na informalidade. O discurso mencionado acima pode ser o reflexo da situação social vivenciada pelo jovem participante do estudo. Durante a entrevista foi visto que Barbarói, Santa Cruz do Sul, n. 52, p.<131-149>, jul/dez, 2018 
mesmo faz parte de uma família que possui condições econômicas favoráveis, que possibilita que esse jovem, diferente de alguns outros das comunidades, tenha sua responsabilidade com o trabalho adiada. No que se refere aos jovens urbanos/as, sabe-se que a depender da condição socioeconômica familiar, alguns e algumas precisam também se dedicar ao trabalho e nem sempre podem dar continuidade ao processo de escolarização.

Ainda, no discurso do jovem acima quando o mesmo afirma “(...) adulto é quem tem responsabilidade, pai de família (...)", nos aponta a ideia do homem provedor do lar, responsável pela família, algo que se faz presente na cultura das comunidades quilombolas. Outro ponto que se considera importante mencionar é o sentir-se jovem para aqueles/as que são casados/as:

P: Você se considera jovem?

Agora que eu tenho 24 anos, tô nova, sou jovem (Mali, F, 24 anos, casada, tem duas filhas).

Essa percepção é divergente nas comunidades estudadas. Independente do estado civil, de terem filhos/as, alguns e algumas se consideram jovens, mas os/as moradores/as adultos e idosos/as não os/as percebem dessa forma. Durante o período que estive nas comunidades observando e participando de alguns momentos junto aos/as quilombolas, quando eu falava sobre a pesquisa, e mencionava que era um estudo com os/as jovens, muitos faziam referência aos alunos/as das escolas da comunidade que possuem 13, 14 anos, que não são casados/as e não têm filhos/as. Com isso percebe-se que para alguns moradores/as o matrimônio e a maternidade/paternidade são marcadores para a vida adulta. Há ainda aqueles/as que atribuem à juventude determinados comportamentos:

Eu não sou jovem mais não, já passei essa fase. Jovem é assim, menina de 10 anos, 12, o quê? 12 abaixo, porque elas só vivem no bar bebendo e fumando, onde é que é criança mais, jovem é esse rapaz que tem aqui no jogo de bola, fica em casa vai brincar mais as meninas, os meninos. Mas, só quer viver em porta de bar com 10, 11 anos, já é uma mulher veia (Rhanda, F, 21 anos).

Pode ser percebido no relato acima que o fato de algumas pessoas frequentarem os bares, beberem e fumarem, comportamentos considerados tipicamente adultos, faz com que não sejam percebidos/as como jovens independente da idade que possuem.

As percepções sobre a juventude nas comunidades são diversas, pois existem aquelas pessoas que se consideram jovens independente do estado civil, há aqueles/as que pautam a juventude através da idade, outros através de comportamentos apresentados por alguns e algumas. Mas existe outra especificidade que faz parte dos/as participantes deste 
estudo que é a identidade quilombola. Pois muitos/a fizeram referência a situações de preconceito por serem quilombolas quando chegam à cidade, sobretudo no espaço escolar. Conforme podemos ver no discurso a seguir:

quando a gente chega na cidade, na escola, o povo fica olhando estranho, fazendo piadinha, óia os matutos do sítio, chamam de macumbeiro quando o grupo de dança se apresenta na escola (Bahati, F, 22 anos).

eu desisti dos estudos, porque na escola na cidade, o povo quere ser melhor do que a gente, eu ficava sozinha lá quando tinha trabalho para fazer em grupo, ninguém queria fazer com eu, aí eu não tava me sentindo bem e desisti (Jamila, F, 24 anos).

$\mathrm{O}$ preconceito e a discriminação têm funcionado como mecanismos de opressão e exclusão, que por vezes são legitimados socialmente, pelos sistemas de segurança, de educação, de saúde, entre outros, principalmente na relação dos quilombolas com a população urbana.

\section{Relação rural - urbana}

Foi visto que há uma circulação dos/as jovens quilombolas entre os contextos rural - urbano. Os/as jovens costumam frequentar a cidade em dias de festa, para fazer compras, passear, ter cuidados em relação à saúde, trabalhar e principalmente para estudar, pois as comunidades, conforme já referido aqui, só possuem escolas onde funciona o ensino fundamental I e II, e os/as quilombolas que desejam concluir o processo de escolarização precisam ir à cidade. Quando não é para estudar, os/as jovens e demais quilombolas vão à cidade a pé, de carro particular, moto particular, moto-táxi, cavalo, pois não existe transporte público que faça o percurso para as comunidades. As questões de classe dificultam um maior contato dos/as jovens com a vida urbana e, consequentemente, com o que essa pode oferecer. Os/as que estudam na cidade vão à mesma em um ônibus cedido pela prefeitura.

Os/as jovens e adultos que moram na cidade, em Garanhuns também costumam frequentar as comunidades rurais, sobretudo, nos finais de semana, onde participam de torneios de futebol aos domingos em que ocorrem os jogos e vão aos bares. Existe um bar na comunidade Estivas que é o mais frequentado pelos/as jovens da cidade. Lá eles e elas dançam, ligam o som de carro, bebem e namoram.

Os espaços rural/urbano ao mesmo tempo em que possibilita que os/as jovens urbanos/as/da cidade e os quilombolas/rurais aproximem-se e vivenciem novas experiências no contexto quilombola, também separa esses/as jovens, haja vista a distância entre os territórios, nas comunidades quilombolas a questão do transporte é complicada, já que não existe transporte público, conforme já referido, e outros marcadores sociais como classe e raça 
que distanciam estes/as jovens, principalmente quando os/as quilombolas chegam à cidade, e muitas vezes sofrem preconceito e discriminação racial. Os relatos a seguir apresentam como ocorre a interação entre os/as jovens quilombolas e urbanos/as nas comunidades:

Vem muita gente da rua nos finais de semana pra os bares. P: Você bebe com essas pessoas? Eu bebia mais com elas antes, que todo domingo eu tava nos bar, em festa, agora depois que eu tive a menina eu não bebo muito com elas não, só, às vezes, que eu vou pra o bar, bebo mais em casa mesmo agora (Mali, F, 24 anos).

"Bebo com as amigas no bar, a gente tem colegas que a gente conhece da rua, aí bebe mais eles, quando eles chega aqui, fica lá todo mundo no bar. É bom lá, a gente conhece outras pessoas, se diverte" (Jamila, F, 18 anos).

O uso de bebidas alcoólicas tem funcionado como uma prática que faz parte da sociabilidade entre os dois mundos: rural-urbano, aproximando os/as jovens no contexto das comunidades. Foi visto também que os/as jovens que não fazem uso de álcool e não frequentam os bares não interagem com os/as urbanos/as no espaço das comunidades do mesmo modo que ocorre com aqueles que bebem. Como é possível observar no relato a seguir: "Tenho uns conhecido que quando chegam mandam uma mensagem pra eu to aqui no bar, eu digo tá certo, porque eu não bebo mais, não tem pra que eu ir, aí mal vejo eles aqui” (Bahati, F, 22 anos).

Os/as jovens sempre que se referem à presença das pessoas da área urbana nas comunidades falam sobre os torneios de futebol e os bares, sobretudo os bares são os mais referidos. Estes têm um papel importante na frequência das pessoas na localidade nos finais de semana e na renda de alguns quilombolas. A partir dessas questões pensa-se que os/as jovens e adultos buscam nas comunidades o lazer e até mesmo um refúgio da vida urbana.

Nos finais de semana é movimentado aqui, passa muitos carros de pessoas que vem de fora pra os bares, tem gente que liga som em casa e fica bebendo, às vezes tem torneio de futebol, aí muita gente vai, é bom aqui. Frequenta gente da rua quando tem alguma reunião, ou algum turista vem aqui conhecer a comunidade, outros veem no final de semana pra os bares que tem aqui, os de lá da Estivas (Thembi, M, 19 anos).

Quando o entrevistado acima Thembi, foi indagado sobre qual seria o motivo das pessoas de Garanhuns irem para os bares da comunidade, já que na cidade também existem muitos bares, ele respondeu:

Vem, não sei explicar porque, deve ser porque é mais reservado ou mais calmo, é sítio ninguém proibi barulho de som, pode ligar a vontade aqui, aí vem de algumas partes de Garanhuns. Vem mulheres também, elas ficam lá dançando, a gente fica olhando. Às vezes a gente bebe também, vamos pro bar, a gente vai beber (Thembi, M, 19 anos). 
É possível observar como o território quilombola é usado pelos/a urbanos/as, as pessoas ficam à vontade, sem proibições. No relato a seguir pode ser visto a descrição de quem são essas pessoas da área urbana que frequentam as comunidades:

\begin{abstract}
Vem mais mulher do que homem, porque quando se chega carro aqui, gente de fora pra beber, vem o quê? Dois homem, três mulher, dois homem, quatro mulher, aí vem mais mulher do que homem de fora, mas daqui tem mais homem do que mulher, porque nem todas vão pra farra, agora de fora se conta assim de monte. Ontem mesmo tava descendo carro aí cheio de gente, topado, mulher, tudo da cidade mesmo. Eles chegam aqui, aí começam a beber, muitos já conhecem os que gostam de farra também e que é daqui, aí chega lá e se mistura tudo, às vezes, não se mistura porque tem o pessoal daqui que não bate bem com alguns e da mesma forma que não se bate bem, tem uns de lá que vem, fala assim, mas não se bate com alguém daqui, ás vezes, porque já quiseram brigar, mas só que fica tudo na deles, você pra lá e eles pra cá, cada um na sua mesa (Rashid, M, 18 anos).
\end{abstract}

Mesmo os/as jovens e adultos da área urbana frequentando Castainho e Estivas, compartilhando os mesmos espaços de sociabilidade dos/as quilombolas, pelo relato acima nos parece que existe uma questão de alguns e algumas jovens que "não se misturam", de justamente buscarem ficar separados/as para mostrar certa superioridade em relação aos/as jovens quilombolas, afirmarem que existe diferença entre eles/as, seja através do tipo de bebida que é consumido, a maioria dos/as jovens da cidade bebem cerveja, seja através da roupa usada, ou do fato de chegarem de carro, ligar o som, já que ter um carro em determinados contextos é ter um status diferenciado.

Os/as jovens urbanos/as frequentam um território que não pertence aos mesmos, mas o fato de terem, muitas vezes, melhor condição financeira, isto proporciona certo status e poder de fazer naquele espaço o que querem, os/as quilombolas geralmente fazem uso de bebidas que têm um custo financeiro menor e nem sempre podem escolher por exemplo, o lugar do bar que querem ficar, a música que desejam ouvir, ou se o volume do som estiver incomodando os/as moradores/as, é difícil chegar e pedir para diminuírem o volume ou desligarem o som. A partir dessas cenas percebe-se o quanto as questões de classe e território produzem situações de opressão e desigualdades.

Foi possível refletir também sobre as mulheres da área urbana de Garanhuns que vão as comunidades e fazem uso de álcool. A ida às comunidades pode ser uma fuga do controle que as mulheres sofrem decorrente das relações de gênero que ocorre também na área urbana, bebendo em outro espaço não correm o risco de ficarem "mal faladas" na cidade. Nas comunidades as mulheres que bebem nos bares são vistas por muitos/as dos/as quilombolas como mulheres que não são "direitas", não servem para casar, se forem casadas e não estiverem acompanhadas pelos maridos, são vistas como irresponsáveis que deveriam 
estar em casa cuidando das tarefas domésticas. Então, para as mulheres da cidade mesmo que a presença das mesmas nos bares das comunidades também seja passível de julgamentos, mas elas retornam a área urbana e estão "livres" dos mesmos.

Isto que remete a pensar sobre as relações de gênero, chama atenção porque é importante ter um olhar ampliado para as diferenças entre mulheres e homens, mulheresmulheres, homens-homens, e neste estudo são ressaltadas estas diferenças na relação com o território e as práticas realizadas no mesmo, a exemplo do uso de álcool. Vale salientar que há um reconhecimento crescente de que todas as mulheres estão, de algum modo, sujeitas ao peso da discriminação de gênero, e fatores relacionados à suas identidades sociais, tais como classe, casta, raça, cor, etnia, religião, origem nacional e orientação sexual, são "diferenças que fazem diferença" na forma como vários grupos de mulheres vivenciam a discriminação (CRENSHAW, 2002).Assim conforme relatado acima, a discriminação vivenciada pelas mulheres urbanas não ocorre da mesma forma que a vivenciada pelas quilombolas, pois os marcadores sociais que as constituem produzem efeitos diferentes.

Outra questão que foi observada e que também está sendo usada pelos/as jovens quilombolas e tem contribuído para aproximar esses/as dos/as urbanos/as, é a internet e as redes sociais, pois se há pouco tempo essa era uma realidade só da área urbana, isso tem mudado. Apesar de que nas comunidades quilombolas ainda são poucas pessoas que possuem em suas casas computador e internet. Alguns e algumas estudantes ganharam tablets na escola que fazia parte de uma ação do Governo do Estado, e estes/as fazem uso das redes para se comunicar com os colegas da escola, fazer pesquisas, e também ter informações sobre o que acontece na cidade. Conforme pode ser visto neste relato: "Os amigos da rua, do colégio, eu converso pelo face, que eles não vem aqui não" (Dara, F, 19 anos).

É afirmado por Castro (2004, p.2) que "as fronteiras rurais e urbanas são constantemente diluídas no cotidiano. Morando em áreas rurais e transitando por áreas urbanas os jovens vivenciam diferentes redes sociais e práticas culturais, compondo uma verdadeira bricolagem de linguagem e comportamentos". E é isso que foi visto como pôde ser observado no relato sobre a comunicação pelo facebook.

Figueiredo (2011) para falar sobre amizade entre negros e brancos, refere-se a uma pesquisa realizada por Pereira (1967) em que foi observado que a convivência e a amizade entre negros e brancos se reduziam ao espaço do trabalho. Na pesquisa com as trabalhadoras domésticas, a autora referida acima percebeu que, na maioria dos casos, a amizade entre patroas e trabalhadoras também se reduz ao espaço doméstico, isto é, com 
raríssima exceção elas são convidadas para ir à praia, ao shopping, visitar a casa de pessoas amigas ou mesmo participar de uma festa de aniversário. A relação de compadrio se dá também sempre na mesma direção: as empregadoras podem se tornar madrinhas das filhas/os das trabalhadoras, mas nunca o contrário.

Importante pensar também sobre as relações de amizade entre os/as jovens quilombolas e urbanos/as, alguns e algumas jovens quilombolas afirmaram que possuem amigos/as da cidade, inclusive que alguns desses/as frequentam as comunidades. Mas, quando indagados se os/as quilombolas costumam frequentar a casa dos/as amigos/as na área urbana, poucos afirmaram essa relação.

Se existem várias pessoas da cidade que vão fazer uso de álcool nas comunidades, há também os/as jovens e adultos quilombolas que vão beber na cidade. Não são muitos os que referiram ter essa prática, mas alguns e algumas relataram que se reúnem e vão beber nos bares da Cohab II, bairro que fica mais próximo a Castainho. Os relatos a seguir exemplificam essa questão: "Eu quando vou pra rua, eu bebo com os daqui mesmo, que a gente vai tudo junto. Mas, vai mais os cara casados já” (Taye, M, 19 anos).

Um fato que também nos chamou atenção no relato do jovem Taye, é que o mesmo fala: "quem mais frequenta os bares da cidade são os homens casados jovens e adultos, e vão juntos com a finalidade de se divertirem e fazerem uso de álcool”. Na pesquisa realizada por Alves e Cantarelli (2010) também foi encontrado que os homens jovens e adultos que residem ou trabalham no campo, preferem a companhia dos amigos ou parentes, em suas horas vagas, distinguindo-se basicamente os programas que se fazem com os amigos, com a família e com a esposa ou namorada, no caso dos solteiros. Em relação aos casados, na referida pesquisa foi encontrado que o lazer na comunidade onde moram ou fora é comumente "regado" a cachaça. Dados que também foram encontrados no presente estudo.

Outra questão é que quando os/as jovens vão se divertir em Garanhuns, frequentam os bairros periféricos da cidade, lugar destinado historicamente aos grupos marginalizados socialmente. As questões de classe e raça/etnia dificultam que os/as jovens frequentem outros espaços na cidade que requerem um gasto financeiro, assim a procura nesses bairros é também pelos bares que são mais acessíveis aos/as jovens quilombolas. Existe nesse sentido uma diferença na ocupação do território entre os/as jovens urbanos/as e os/as quilombolas. Quando os/as urbanos/as vão à comunidade, usufruem dos espaços sem que haja nenhuma interdição, ligam som do carro em alto volume, bebem, fazem o que querem, e o mesmo não ocorre quando são os/as quilombolas que estão na cidade. Foi 
observado esse fato também quando os/as jovens foram indagados, se os mesmos/as percebiam alguma diferença entre os/as jovens quilombolas e os/as jovens urbanos/as, um deles respondeu:

\begin{abstract}
A diferença que eu percebo ao mesmo tempo eu nem ligo, ignoro porque os jovens daqui, por exemplo, vem gente da cidade, os jovens de lá, vem pra aqui, aí eles chegam aqui, não tem nenhum tipo de ser ignorado nem nada. Chega aqui ninguém faz nada com eles, e, às vezes, a gente saí daqui pra lá, que tem algumas Cohabs, e eles ficam marcando a gente querendo fazer alguma maldade, quer dizer ainda tem preconceito. Tem muitos que quando sabe que é do Castainho, eles considera a pessoa, sábado mesmo que passou eu saí com os meninos pra Cohab, a gente foi olhar uma quadrilha, aí uns cara lá ficou com encrenca pra nosso lado, querendo brigar, aí a gente disse não, nós não quer brigar não, vamos simbora, aí teve outro que chegou e disse ninguém vai mexer com os meninos aí não que eles são lá do Castainho, eu conheço tudo, aí eles ficaram na dele, mas se não tivesse esse que defendesse a gente, eles iriam querer confusão com a gente (Rashid, M,18 anos).
\end{abstract}

No discurso acima fica visível como o território é usado de maneira desigual entre os/as jovens. Mais uma vez pode-se perceber o quanto os/as jovens quilombolas sofrem discriminação na cidade, e o quanto são privados de usufruir o que esta possui. Os marcadores de raça/etnia e classe estão presentes reforçando as desigualdades sociais e a exclusão a que os/as mesmos/as ficam sujeitos/as.

A violência racial constitui um constante ataque às identidades e subjetividades dos/as excluídos/as, e estabelece o padrão cultural dominante, capitalista, branco e androcêntrico ao qual a população negra é constantemente pressionada a se adaptar e moldar. A dominação racial estabelece ao racialmente dominado o lugar da desonra, o lugar de objeto do desejo do outro. O racismo, o sexismo e a classe social se reforçam mutuamente, na medida em que ocorre uma potencialização entre a dominação racial/étnica e a dominação de gênero e fazem com que grupos racialmente dominados estejam como que circulando por territórios de outrem (ANJOS, 2004). Observou-se também essas questões nos discursos de alguns e algumas jovens que disseram não se sentir bem na cidade por não serem bem vistos lá.

Viu-se também que alguns jovens acham que a cidade é um lugar tranquilo, que tem muitos lugares para passear, é melhor para conseguir um trabalho. Outros/as acham a cidade muito agitada, muita gente, não gostam de ficar lá, só vão quando precisam comprar alguma coisa ou resolver algo.

“A vida na rua é mais tranquila eu acho, tem canto que pra pessoa passear é tão bom, aqui no sítio é um barulho, o povo brigando, o povo se matando aqui, na cidade vai ter uma coisa ou outra, mas não é como aqui” (Gina, F, 22 anos). 
Essas brigas a que a jovem acima faz referência geralmente ocorrem entre pessoas sob o efeito do álcool, e é bastante comum nas comunidades, sobretudo nos finais de semana que é o período em que os/as moradores costumam fazer uso de bebidas com um padrão mais elevado.

Alguns e algumas jovens quilombolas fizeram referência à frequência das pessoas nas comunidades como algo positivo, que gostam muito da presença das pessoas da cidade, porque conhecem novas pessoas, a comunidade fica movimentada, animada.

A relação rural-urbana é perpassada por várias questões, foi possível observar que os marcadores de gênero, classe e raça/etnia produzem as situações desiguais entre os/as jovens quilombolas e urbanos/as em ambos os contextos comunidade - cidade. TraversoYepez e Pinheiro (2005) pontuam que as inserções de classe social e gênero em uma mesma sociedade, ao configurarem contextos de interação específicos, repercutem de forma substancial nos processos de subjetivação de cada pessoa, delineando possibilidades e limitações. Foi isto que ocorre na trajetória dos/as jovens quilombolas na relação com os/as urbanos/as.

\section{Considerações finais}

Foi possível refletir sobre essa relação entre os/as jovens urbanos/as e os/as quilombolas, esses/a últimos/as quando chegam à cidade sofrem vários tipos de preconceito e discriminação por serem quilombolas, alguns e algumas por terem o fenótipo negro/a e, em alguns lugares por serem moradores/as das áreas rurais, vistos como os "matutos" do "sítio". Situações que têm efeitos e implicações nos processos de subjetivação dos/as mesmos/as, o que faz com que alguns e algumas não queiram ir estudar na cidade, se considerem incapazes de conseguir um emprego formal, entre outras questões. Pois, ora esses/as jovens levantam suspeitas por serem negros/as, são vigiados nos lugares que frequentam, considerados um risco a sociedade, ora são alijados de vários de seus direitos, ao acesso à educação de qualidade, a saúde, o lazer, o mercado de trabalho, entre outras esferas. Com isso chama-se atenção para o modo como os sistemas raça, classe e território produzem esse/as jovens e o quanto essas questões precisam ser melhores discutidas em vários espaços. As políticas para juventude precisam considerar essa realidade tão presente na vida de muitos dos/as jovens a fim de garantir uma vida digna para os/as mesmos/as. 
Quando foi observado o uso do território quilombola e urbano de modo desigual por jovens quilombolas e urbanos, em que os/as quilombolas têm restrições que não se fazem presentes para os/as urbanos/as, pode ser pensado: esse encontro entre as juventudes favorece a vida dos/as quilombolas ou contribui para reforçar as situações de desigualdades e opressão que os/as quilombolas já tanto vivenciam?

Pensar também nas idas e vindas dos/as jovens rurais faz refletir sobre a estrutura fundiária do país, na distribuição desigual dos serviços públicos, nas políticas públicas para o meio rural. A situação de isolamento que ainda alguns contextos rurais vivenciam, onde faltam escolas e, quando essas existem não atendem todas as demandas. $\mathrm{O}$ mesmo acontece em relação aos serviços de saúde, às atividades de lazer, o que dificulta a vida dos/as jovens e faz com que alguns e algumas frequentem as áreas urbanas não apenas como um lugar a mais de opção de lazer, de encontro com outras pessoas, mas como o lugar da busca por questões básicas de sobrevivência, a exemplo da procura por um atendimento médico.

\title{
THE BORDERS (IN) VISIBLE BETWEEN THE QUILOMBOLA AND URBAN YOUTH
}

\begin{abstract}
In the present study, we observed some aspects that emerge from the encounters between the young rural quilombolas and the urban ones. Through the quilombolas young we seek to know how these encounters happen. Quilombolas are part of a survey conducted in two communities, located in the rural area of the municipality of Garanhuns / PE, whose names are Castainho and Estivas. The research was carried out in two moments: in the first we did participant observation in the communities, then 20 semi-structured interviews with the young people. The constructed data were analyzed from the intersectionality of gender, race and social class. We have seen that young urban people attend quilombola communities, mainly on weekends, where they have leisure practices. The quilombolas young attend the urban area with different purposes: studies, work, parties. We realize that this encounter between the youths in the quilombola context, is often crossed by situations of oppression and inequalities. Urban young people make use of quilombola territory without restrictions, turn on loud music, drink, choose the place of the bar where they want to stay, the same does not happen when quilombolas are in the city. The unequal relations of class, race and gender are marked in the Quilombola itself, like the urban youths who frequent the communities, but do not "mix" with the people there. We consider it important to observe this reality, since we seek to understand the experiences of young people in order to visualize limits and possibilities that circumscribe the life of youth.
\end{abstract}

Keywords: quilombolas young; Urban young; Intersectionality

\section{LAS FRONTERAS (IN) VISIBLES ENTRE LA JUVENTUD QUILOMBOLA Y} URBANOS

Barbarói, Santa Cruz do Sul, n. 52, p.<131-149>, jul/dez, 2018 


\section{RESUMEN}

En el presente estudio, podemos observar algunos aspectos que emergen de los encuentros entre rural y quilombola y juventud urbana. A través de quilombolas jóvenes, buscamos saber cómo ocurren estos encuentros. Los quilombolas forman parte de una investigación realizada en dos comunidades, ubicadas en el área rural de Garanhuns / PE, cuyos nombres son Castainho y Estivas. La investigación fue conducida en dos momentos: en el primero, la observación participante ocurrió en las comunidades, a continuación, 20 entrevistas semiestructuradas con los jóvenes. Los datos construidos se analizaron sobre la base de la intersección de género, raza y clase social. Se verificó que las comunidades de quilombolas frecuentes en jóvenes urbanos, principalmente los fines de semana, donde tienen actividades de ocio. Los jóvenes quilombolas frecuentan el área urbana con diferentes propósitos: estudios, trabajo, fiestas. Se percibe que este encuentro entre los jóvenes en el contexto de los quilombolas, muchas veces, es atravesado por situaciones de opresión y desigualdades. Los jóvenes urbanos usan territorio quilombola sin restricciones, conectan el sonido en alto volumen, beben, escogen el lugar donde quieren quedarse en el bar, lo mismo no ocurre cuando los quilombolas están en la ciudad. Las relaciones desiguales de clase, raza y género están marcadas en el propio territorio de Quilombola, como la juventud urbana que frecuenta las comunidades, pero no está "mezclada" con las personas allí. Se considera importante observar esta realidad, pues se ha buscado comprender las experiencias de los jóvenes, a fin de hacer visibles límites y posibilidades que circunscriban la vida de la juventud.

Palabras clave: quilombolas jóvenes; juventud urbana; interseccionalidad

\section{REFERÊNCIAS}

ALMEIDA, Eliane de Souza. Ilusão e realidade em Ivaporunduva: a televisão na cultura quilombola. Análise a partir da Folkmídia. 2005. 200 f. Dissertação (Mestrado em Comunicação Social) - Universidade Metodista de São Paulo, São Bernardo do Campo, 2005.

ALVES, Maria de Fátima Paz; CANTARELLI, Jonnhy. Ser um homem de respeito: masculinidade, sexualidade e relações de gênero na perspectiva de homens rurais de um município da Zona da Mata pernambucana. In: SCOTT, Parry; CORDEIRO, Rosineide (Org.). Agricultura familiar e gênero: práticas, movimentos e políticas públicas. 2 ed. Recife: Ed. Universitária da UFPE, 2010. p. 301-320.

ANJOS, José Carlos dos. Etnia, raça e saúde: sob uma perspectiva nominalista. In: MONTEIRO, S.; SANSONE, L. (Org.). Etnicidade na América Latina: um debate sobre raça, saúde e direitos reprodutivos. Rio de Janeiro: Editora Fiocruz, 2004. p. 97-119. Disponível em:<http://search.bvsalud.org/cvsp/resource/pt/lil-387847>. Acesso em 12 de junho de 2017.

ANJOS, Rafael Sanzio Araújo dos. Quilombolas. Tradições e cultura de resistência. São Paulo: Aori comunicação, 2006.

BASTOS, Priscila da cunha. Entre o quilombo e a cidade: trajetórias de individuação de jovens mulheres negras. 2009. 102 f. Dissertação. (Mestrado em Educação) -Universidade Federal Fluminense, Niterói, 2009. 
BRAH, Avtar. Diferença, diversidade, diferenciação. Cadernos Pagu. (26), 2006. p. 329-376. Disponível em: $<$ http://www.scielo.br/pdf/cpa/n26/30396.pdf > . Acesso em: 08 de agosto de 2017.

CARNEIRO, Maria José. O ideal rurbano: campo e cidade no imaginário de jovens rurais. In: SILVA, Francisco Carlos Teixeira da et al. (Org.). Mundo rural e política. Rio de Janeiro: Campus, 1998. p. 97-117.

CASTRO, Elisa Guaraná de. As jovens rurais e a reprodução social das hierarquias. In: WOORTMANN, Elen F; MENACHE, Beatriz (Org.). Margarida Alves - Coletânea

sobre estudos rurais e gênero. Brasília: MDC, ICA, 2006. p. 245-277.

CASTRO, Elisa Guaraná de. Sonhos, desejos e a realidade: herança, educação e trabalho de jovens rurais da Baixada Fluminense/RJ. In: I Simpósio Internacional de Juventude Brasileira - JUBRA. Rio de Janeiro: UFRJ, 2004. Disponível em:< http://www.nead.gov.br/portal/nead/arquivos/view/textos-digitais/Artigo/arquivo_298.pdf >. Acesso em: 31 de agosto de 2017.

. As jovens rurais e a reprodução social das hierarquias. In: WOORTMANN, Elen F; MENACHE, Beatriz (Org.). Margarida Alves - Coletânea sobre estudos rurais e gênero. Brasília: MDC, ICA, 2006. p. 245-277.

CRENSHAW, Kimberlé. Documento para o encontro de especialistas em aspectos da discriminação racial relativos ao gênero. Rev. Estudos feministas. Ano 10 (172), 2002. p. 171-188. Disponível em:< http://www.scielo.br/pdf/ref/v10n1/11636.pdf >. Acesso em: 20 de março de 2017.

.Demarginalizing the Intersection of Race and Sex: A Black Feminist Critique of Antidiscrimination Doctrine, Feminist Theory, and Antiracist Politics. University of Chicago Legal Forum, 14, 1989, p. 538-54. Disponível em:<

http://chicagounbound.uchicago.edu/cgi/viewcontent.cgi?article $=1052 \&$ context $=$ uclf $>$. Acesso em: 20 de março de 2017.

CRUZ, Valter do Carmo. Territorialidades, identidades e lutas sociais na Amazônia. In: ARAÚJO, Frederico G. B. de; HAESBAERT, R. (Org.). Identidades e Territórios: questões e olhares contemporâneos. Rio de Janeiro: Ed. Access, 2007. p. 93 - 122.

FIGUEIREDO, Angela. Condições e contradições do trabalho doméstico em Salvador. In: MORI, Natalia et al (Orgs.). Tensões e experiências: um retrato das trabalhadoras domésticas de Brasília e Salvador. Brasília: CFEMEA: MDG3 Fund, 2011. Pp. 89-132.

GOMES, Flávio dos Santos. Quilombos/Remanescentes de quilombos. In: SCHWARCZ, Lília M.; GOMES, Flávio. (ORGs.) Dicionário da Escravidão e liberdade: 50 textos críticos. São Paulo: Compainha das Letras, 2018. pp. 367-373.

GOMES, Christianne et al. Lazer na America Latina/Tiempo libre, ócio y recreación em Latinoamérica. $2^{\text {a }}$ Ed. Belo Horizonte: UFMG, 2009.

PEREIRA, Jorge Luiz de Goes. Entre campo e cidade: amizade e ruralidade segundo jovens de Nova Friburgo. Estudos Sociedade e Agricultura. Vol. 12. No. 2. p. 322-352, 2004.

Disponível em:< http://r1.ufrrj.br/esa/V2/ojs/index.php/esa/article/view/253>. Acesso em 20 de dezembro de 2016. 
PISCITELLI, Adriana. Interseccionalidades, categorias de articulação e experiências de migrantes brasileiras. Sociedade e Cultura. Vol. 11, nº 2, jul-dez, p. 263-274, 2008.

Disponível em:<https://www.revistas.ufg.br/fchf/article/view/5247/0>. Acesso em: 20 de fevereiro de 2016.

SANTANA, Katiuscy Carneiro; TELES, Nair; OLIVEIRA, Maria Helena Barros de. Direito à saúde: adolescentes quilombolas em comunidades rurais de Vitória da Conquista (BA). In: OLIVEIRA, Maria Helena Barros de, et al (Orgs). Direitos humanos e saúde: construindo caminhos, viabilizando rumos. CEBES: Rio de Janeiro, 2017, p. 53-68. Disponível em:< http://cebes.org.br/site/wp-content/uploads/2017/05/Dihs-final-web.pdf >. Acesso em 30 de abril de 2017.

TRAVERSO-YÉPEZ, Martha. A.; PRINHEIRO, Verônica de Souza. Socialização de gênero e adolescência. Estudos Feministas. Vol.13, n 1, Florianópolis, 2005. P147-162.

Dispon[ivel em <http://www.scielo.br/pdf/ref/v13n1/a10v13n1.pdf>. Acesso em: 20 de fevereiro de 2016.

WANDERLEY, Maria de Nazareth Baudel.Jovens rurais de pequenos municípios de Pernambuco: que sonhos para o futuro. In: CARNEIRO, Maria José; CASTRO, Elisa Guaraná de (Org.). Juventude rural em perspectiva. Rio de Janeiro: Mauad X, 2007. p. 2133.

\section{Sobre os autores}

Roseane Amorim da Silva é psicóloga, Mestre em Psicologia e Doutora em Psicologia pela Universidade Federal de Pernambuco (UFPE). Endereço eletrônico: roseane_amorim6@hotmail.com

Jaileila de Araújo Menezes é psicóloga, doutora em Psicologia e professora da Universidade Federal de Pernambuco (UFPE). Endereço eletrônica: leilaufrj@ hotmail.com 